\section{Overdominance and Epistasis Are Important for the Genetic Basis of Heterosis in Brassica rapa}

\author{
De-Kun Dong \\ Institute of Vegetable Science, Zhejiang University, 268\#, Kaixuan Road, \\ Hangzhou, 310029, China
}

Jia-Shu Cao ${ }^{1}$
Institute of Vegetable Science, Zhejiang University, 268\#, Kaixuan Road,
Hangzhou, 310029, China; and Key Laboratory of Horticultural Plant
Growth, Development and Biotechnology, Agricultural Ministry of China,
Hangzhou, 310029, China

Kai Shi

Institute of Vegetable Science, Zhejiang University, 268\#, Kaixuan Road, Hangzhou, 310029, China

\section{Le-Cheng Liu}

Institute of Vegetable Science, Zhejiang University, 268\#, Kaixuan Road, Hangzhou, 310029, China; and College of Horticulture and Gardening, Yangtze University, Jingzhou, Hubei, 434025, China

Additional index words. Brassica rapa, epistasis, heterosis, overdominance, quantitative trait locus (QTL)

\begin{abstract}
To investigate the genetic basis of heterosis in Brassica rapa, an $\mathrm{F}_{2}$ population was produced from the cross of $B$. rapa $L$. subsp. chinensis (L.) Hanelt and $B$. rapa $L$. subsp. rapifera Metzg. Trait performances of the $F_{1}$ hybrid showed evident mid parent heterosis, which varied from $18.55 \%$ to $101.62 \%$ for the 11 traits investigated. A total of 23 main effect quantitative trait loci (QTLs) were detected for biomass and its component traits, which could explain $4.38 \%$ to $47.80 \%$ of the phenotypic variance, respectively. Sixty-five percent of these QTLs showed obvious overdominance. Epistasis analysis detected 444 two-locus interactions for the 11 traits at the threshold of $P<0.005$. Some of them remained significant when more stringent threshold were set. These results suggested that overdominance and epistasis might play an important role as the genetic basis of heterosis in $B$. rapa.
\end{abstract}

Plants in Brassica genus are grown worldwide not only as a well-known vegetable, but also one of the most important sources of edible oil. Heterosis for seed yield, biomass, disease and lodging resistance, oil content, and other agronomic characters in Brassica have been well documented (Falk et al., 1994; Pradhan et al., 1993; Schuler et al., 1992; Shen et al., 2005). Most researches on heterosis were focused on the relationship between heterosis and genetic diversity (Ali et al., 1995; Riaz et al., 2001; Yu et al., 2005), combining ability (Brandle and McVetty, 1989; Teklewold and Becker, 2005) or different cytoplasm (Riungu and McVetty, 2004) and others. However, the genetic basis underlying heterosis remains more or less unclear.

Two classic explanations for heterosis, i.e., the overdominance hypothesis (East,

\footnotetext{
Received for publication 26 Jan. 2007. Accepted for publication 8 Mar. 2007.

This work was supported by The Research Fund for the Doctoral Program of Higher Education (20030335117) from Ministry of Education of China, and Key Project for Science and Technology of Zhejiang Province (2005C12019-2).

${ }^{1}$ To whom reprint requests should be addressed; e-mailjshcao@zju.edu.cn
}

1908; Shull, 1908) and the dominance hypothesis (Bruce, 1910; Jones, 1917; Keeble and Pellew, 1910), have been proposed and competed for nearly a century. No proper ways could exactly distinguish and assess these hypotheses until molecular biology technologies and quantitative trait locus (QTL)-based analysis methodology were widely used in genetic analysis in the last 2 decades. Xiao et al. (1995) studied the QTL patterns of a set of $\mathrm{BC}_{1} \mathrm{~F}_{7}$ lines and compared the trait performances of $F_{1}$ and $F_{8}$ populations of an intersubspecific cross of rice and concluded that dominance complementation is the major genetic basis of heterosis. However, an increasing number of studies in maize (Song and Messing, 2003; Stuber et al., 1992), arabidopsis (Mitchell-Olds, 1995), rice (Abdelkhalik et al., 2005; Li et al., 2001; Luo et al., 2001), aspen ( $\mathrm{Li}$ and $\mathrm{Wu}$, 1996), and other plants showed that overdominance plays an important role in the formation of heterosis. These two hypotheses share a common character in that they both were based on only single-locus analysis.

Considering the multigenic nature of quantitative traits, epistasis should not be ignored when exploring heterosis because most traits composing heterosis are complex quantitative traits. Two approaches are often used to measure epistasis in an evolutionary genetic context; one is to use specific mutations and the other is to follow a form of QTL mapping (Malmberg et al., 2005). Several computer programs, including Epistat (Chase et al., 1997), EPISTACY (Holland, 1998), QTLmapper (Wang et al., 1999), Preudomarker (Sen and Churchill, 2001), BQTL (Borevitz et al., 2002), R/qtl (Broman et al., 2003), WinQTLCart (Wang et al., 2006), and QTLNetwork (Yang et al., 2005), can be used to perform epistasis QTL analysis through different methods. Recently, as an important genetic basis of complex traits, epistasis has been reported in a growing body of data based on QTL mapping analyses (Hua et al., 2003; Malmberg et al., 2005; Yu et al., 1997) and has become the third classic explanations for heterosis.

To investigate the genetic basis underlying heterosis in B. rapa, an $\mathrm{F}_{2}$ population was produced from an intersubspecific hybrid between pakchoi [Brassica rapa L. subsp. chinensis (L.) Hanelt] and turnip (B. rapa L. subsp. rapifera Metzg); trait performance, QTL patterns, and two-locus epistasis of 11 traits (including three composite traits and eight component traits) were subsequently analyzed.

\section{Materials and Methods}

An $F_{2}$ population was produced from a cross between two inbred lines of brassica, i.e., Brassica rapa L. subsp. chinensis (L.) Hanelt cv. 'Aijiaohuang' and B. rapa subsp. rapifera Metzg. cv. 'Baimanjing'. The seeds of parents, $F_{1}$ and $F_{2}$ populations, were sown in a seedling bed in on 28 Sept. 2004. The seedlings were transferred to the field $20 \mathrm{~d}$ later.

Three composite traits, i.e., biomass (BM), overground weight (OGWT), and taproot weight (TRWT), and eight component traits, including plant height $(\mathrm{PH})$, plant widths 1 and 2 (PW1 and PW2), leaf length (LL), leaf width (LW), leaf number (LN), and taproot diameters 1 and 2 (TRD1 and TRD2), were investigated $70 \mathrm{~d}$ after transplanting. $\mathrm{PH}$ indicates the natural height of a plant in growth. PW1 and PW2 denote the plant's maximal width passing through axes and the value in the cross direction. TRD1 and TRD2 mean the root's maximal diameter and the value in the cross direction, respectively. LL and LW represent the length and width of the biggest leaf. BM, OGWT, and TRWT are expressed in fresh weight.

One hundred eighty $F_{2}$ progenies were genotyped using 195 Amplified Fragment Length Polymorphism (AFLP) markers. Seventeen markers were excluded from linkage analysis for bias from the segregation ratio of 3:1 (for dominant markers) or 1:2:1 (for codominant markers) by $\chi^{2}$ test. Mapmaker/ EXP 3.0 (Lander et al., 1987; Lincoln et al., 1992) was used to perform the linkage analysis One hundred forty-one AFLP markers were grouped into 17 linkage groups at logarithm of odds (LOD) 3.0 and then ordered at LOD 2.0. Kosambi mapping function (Kosambi, 1944) was used to convert recombination fraction to 
map distance in centiMorgans (cM). Finally, a genetic linkage map spanning $2063 \mathrm{cM}$, composing 13 major linkage groups and four triplets, was constructed. Genetic distance between adjacent markers ranged from 0.4 to $37.3 \mathrm{cM}$ and averaged $16.6 \mathrm{cM}$.

Composite interval mapping was performed using WinQTLCart version 2.5. The setting used was a walk speed of $2 \mathrm{cM}$, model 6 standard, regression method 1 forward. The threshold of LOD greater than 2.5 was chosen for claiming a putative QTL. EPISTACY v2.0 was used to perform two-locus epistasis analysis without considering the already identified main QTLs by composite interval mapping. EPISTACY was run in the SAS system for windows v8.0 (SAS Institute,
2000 ) with a threshold $P$ value of $<0.005$. All interactions were removed in the outputs when the two interacting markers were within $50 \mathrm{cM}$ of each other to avoid linkage effects.

Shapiro-Wilk normality test and other statistical analysis were performed using the SAS system for windows v8.0. Better parent heterosis $(\mathrm{BPH})$ was calculated as $\mathrm{BPH}=\left(\mathrm{F}_{1}-\mathrm{BP}\right) / \mathrm{BP}$, where $\mathrm{F}_{1}$ and $\mathrm{BP}$ mean the performances of hybrid and the better parent. Midparent heterosis (MPH) was calculated as $\mathrm{MPH}=\left(2 \mathrm{~F}_{1}-\mathrm{P} 1-\mathrm{P} 2\right) /(\mathrm{P} 1+\mathrm{P} 2)$, where $\mathrm{P} 1$ and $\mathrm{P} 2$ mean the performances of parents. Figures were plotted using OriginPro 7.5 (OriginLab Corporation, 19912003).
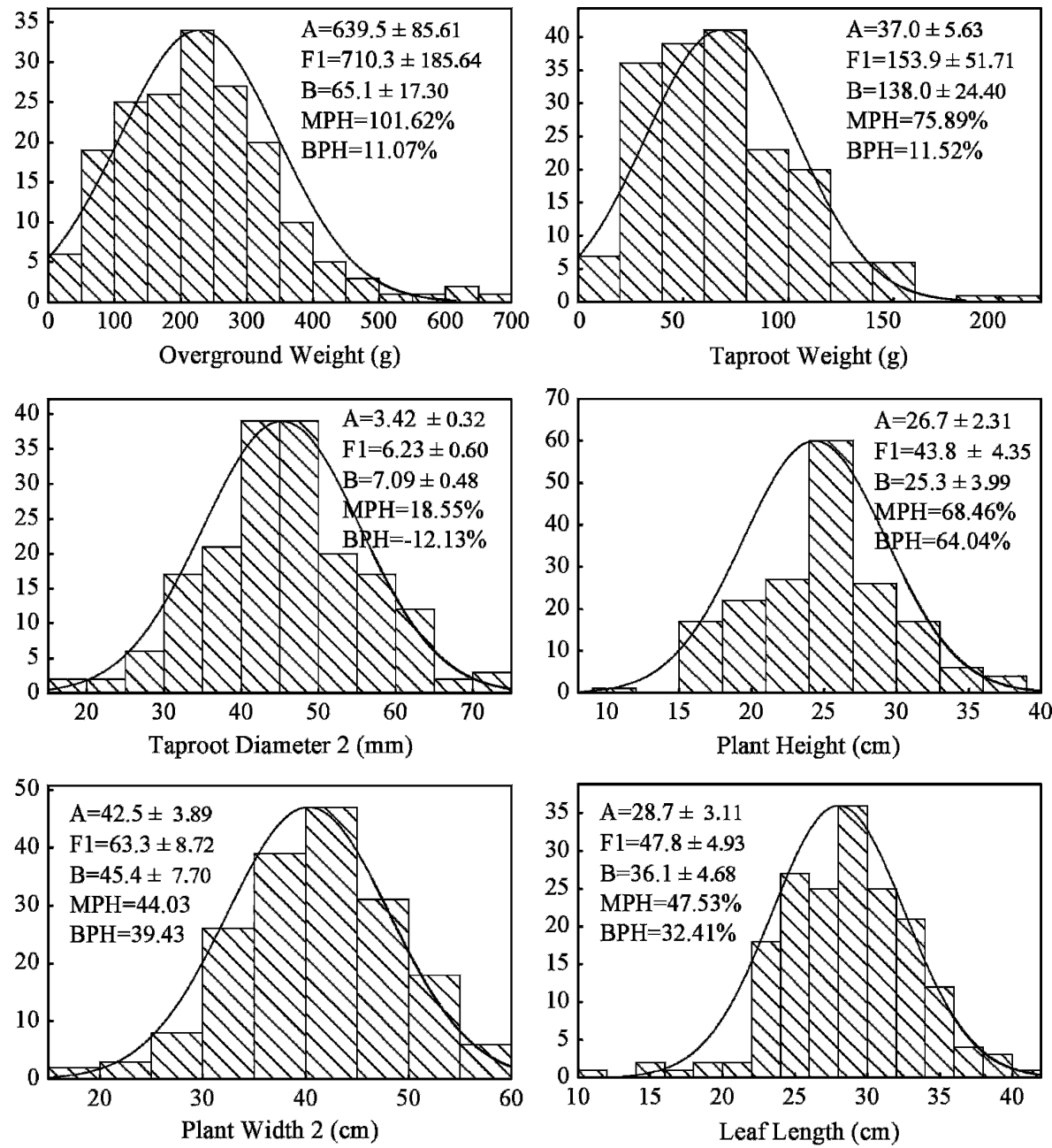

All traits investigated were continuously distributed (Fig. 1). Shapiro-Wilk test showed that TD1, TD2, PH, PW1, and PW2 also fit normal distribution. Significant amount of $\mathrm{MPH}$, which ranged from $18.55 \%$ to $101.62 \%$, was observed in these traits. The BPH varied from $-12.13 \%$ to $64.04 \%$. The composite traits BM, OGWT, and TRWT showed higher heterosis than their component traits.

A total of 23 main effect QTLs for biomass and its component traits were detected by composite interval mapping, one to three QTLs for each trait (Table 1). The phenotypic variance explained by a single QTL ranged from $4.38 \%$ to $47.80 \%$, and QTLs for each
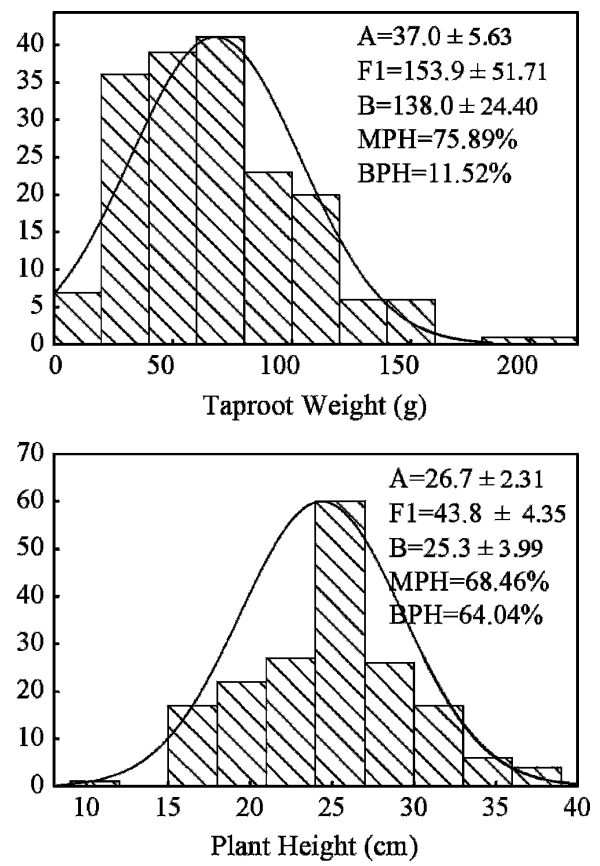
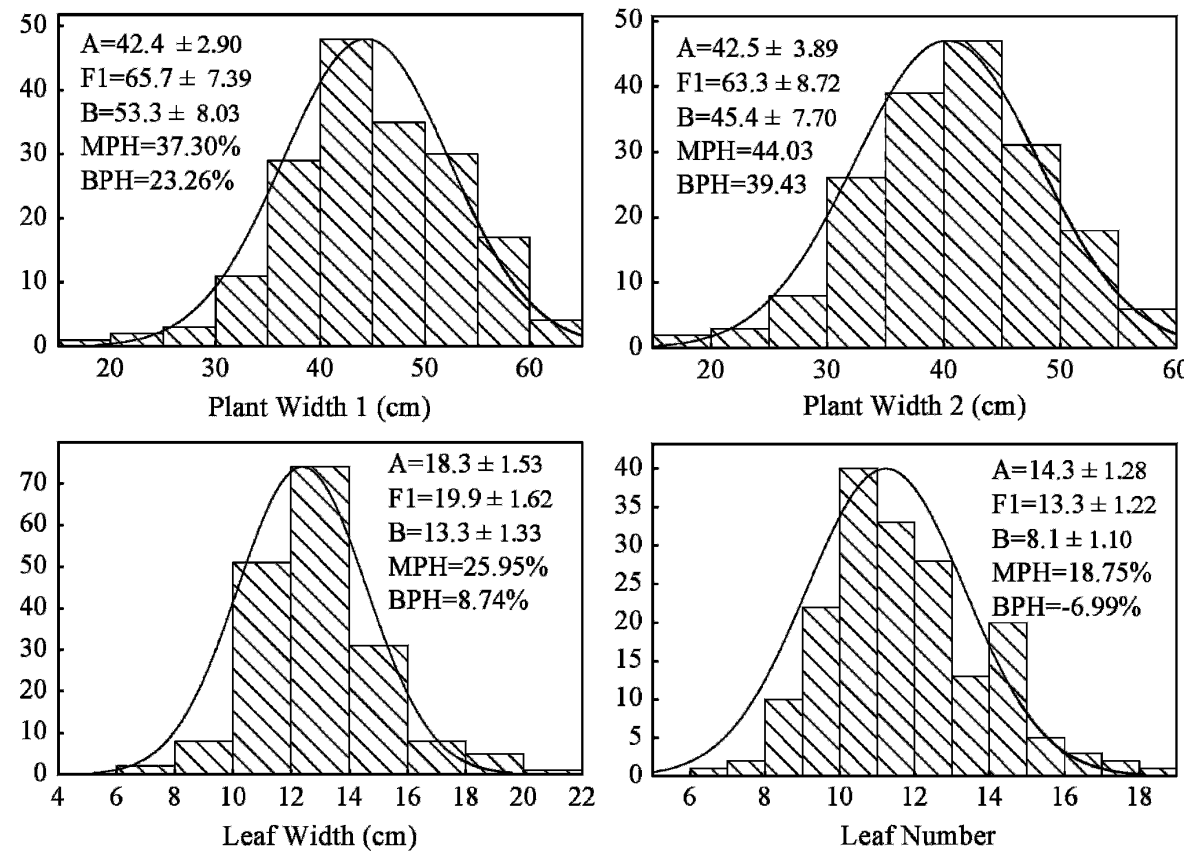

Fig. 1. Distribution of the 11 traits in the $\mathrm{F}_{2}$ population and their performance in $\mathrm{F}_{1}$ and their parents. Equations show the performance of parent $A$ ('Aijiaohuang'), $\mathrm{B}$ ('Baimanjing'), and their $\mathrm{F}_{1}$ offspring. MPH and $\mathrm{BPH}$ denote midparent heterosis and better parent heterosis, respectively. 
trait can account for $16.96 \%$ to $61.59 \%$ of the total phenotypic variance.

Only one QTL for biomass was detected on linkage group 10. It could explain $24.87 \%$ of phenotypic variance and had the same position with a QTL of OGWT. Positive additive effect indicated that the increasing effects were contributed by 'Aijiaohuang'.

Fifteen QTLs were found for OGWT and its component traits, i.e., PH, PW1, PW2, LL, LW, and LN. The QTL positions of OGWT and its component traits on linkage group 8 overlapped each other (Fig. 2A), and their effects also showed identical sign. Overdominance, which means the ratio of dominant effects to additive effect larger than unity, was observed at 11 of the 13 QTLs for the OGWT components traits, whereas the QTLs for OGWT only exhibited partial dominance.

There were seven QTLs detected for TRWT and its component traits, three for
TRWT and two for TRD1 and TRD2, respectively. Close QTL positions and similar effects for TRD1 and TRD2 were detected on both linkage group 3 and 7. The QTLs for these two traits on linkage group 3 explained $34.27 \%$ and $45.18 \%$ of the phenotypic variance, respectively. They also corresponded to a QTL for TRWT judged by mapping positions (Fig. 2B) and explained $8.05 \%$ of its phenotypic variance. The increasing effects for TRWT and its component traits were mainly contributed by parent 'Baimanjing', which has a storage root. In addition, it was greatly different between the performance of TRWT and OGWT in that all the QTLs for the former showed overdominance, whereas only onefourth for the latter did so.

A total of 461 two locus interactions were detected by EPISTACY with the criteria of $P<0.005$. Seventeen interactions were removed from this result because the two

Table 1. Main effect QTLs detected for biomass and its component traits by composite interval mapping.

\begin{tabular}{|c|c|c|c|c|c|c|c|}
\hline Trait & $\begin{array}{l}\text { QTL } \\
\text { no. }\end{array}$ & $\begin{array}{l}\text { Linkage } \\
\text { group no. }\end{array}$ & $\begin{array}{l}\text { Position } \\
\text { (cM) }\end{array}$ & $\begin{array}{l}\text { LOD } \\
\text { score }\end{array}$ & $\begin{array}{c}\text { Additive } \\
\text { effect }\end{array}$ & $\begin{array}{c}\text { Dominant } \\
\text { effect }\end{array}$ & $\begin{array}{l}\mathrm{R}^{2} \\
(\%)\end{array}$ \\
\hline Biomass & 1 & 10 & 62.61 & 4.14 & 129.86 & 88.88 & 24.87 \\
\hline \multicolumn{8}{|c|}{ Overground weight and its component traits } \\
\hline \multirow[t]{2}{*}{ Overground weight } & 1 & 8 & 84.11 & 4.59 & 129.77 & 108.06 & 47.80 \\
\hline & 2 & 10 & 62.61 & 3.35 & 70.61 & 66.66 & 13.79 \\
\hline \multirow[t]{2}{*}{ Plant height } & 1 & 4 & 136.81 & 4.03 & -4.73 & 4.46 & 22.14 \\
\hline & 2 & 8 & 78.11 & 3.77 & 2.83 & 4.77 & 11.58 \\
\hline \multirow[t]{3}{*}{ Plant width 1} & 1 & 3 & 33.41 & 2.53 & -3.45 & -5.27 & 8.69 \\
\hline & 2 & 8 & 76.11 & 3.00 & 3.22 & 6.32 & 6.89 \\
\hline & 3 & 9 & 110.71 & 2.56 & -3.36 & 5.51 & 8.54 \\
\hline Plant width 2 & 1 & 8 & 76.11 & 4.33 & 5.28 & 6.12 & 16.96 \\
\hline \multirow[t]{3}{*}{ Leaf length } & 1 & 2 & 6.01 & 2.63 & -1.64 & -0.62 & 5.85 \\
\hline & 2 & 8 & 76.11 & 5.23 & 1.95 & 5.41 & 7.66 \\
\hline & 3 & 15 & 6.01 & 3.07 & -2.34 & 2.97 & 12.98 \\
\hline Leaf width & 1 & 8 & 72.61 & 4.36 & 1.52 & 1.97 & 19.82 \\
\hline \multirow[t]{3}{*}{ Leaf number } & 1 & 1 & 293.11 & 4.07 & 1.34 & -2.01 & 18.14 \\
\hline & 2 & 8 & 80.11 & 3.03 & 0.80 & 1.87 & 6.13 \\
\hline & 3 & 12 & 16.01 & 2.58 & 1.14 & -2.29 & 13.50 \\
\hline \multicolumn{8}{|c|}{ Taproot weight and its component traits } \\
\hline \multirow[t]{3}{*}{ Taproot weight } & 1 & 3 & 22.01 & 2.65 & -14.86 & -25.91 & 8.05 \\
\hline & 2 & 4 & 99.31 & 2.53 & 14.44 & 24.72 & 4.38 \\
\hline & 3 & 11 & 4.01 & 2.75 & -14.57 & 25.39 & 8.53 \\
\hline \multirow[t]{2}{*}{ Taproot diameter 1} & 1 & 3 & 20.01 & 4.50 & -9.47 & -10.08 & 34.27 \\
\hline & 2 & 7 & 0.01 & 3.49 & -4.83 & -2.35 & 9.94 \\
\hline \multirow[t]{2}{*}{ Taproot diameter 2} & 1 & 3 & 18.01 & 2.86 & -10.26 & -9.80 & 45.18 \\
\hline & 2 & 7 & 0.01 & 3.13 & -3.94 & -3.20 & 7.82 \\
\hline
\end{tabular}

$\mathrm{R}^{2}$ means the percentage of phenotypic variation explained by a QTL.

$\mathrm{QTL}=$ quantitative trait locus; LOD = logarithm of odds.
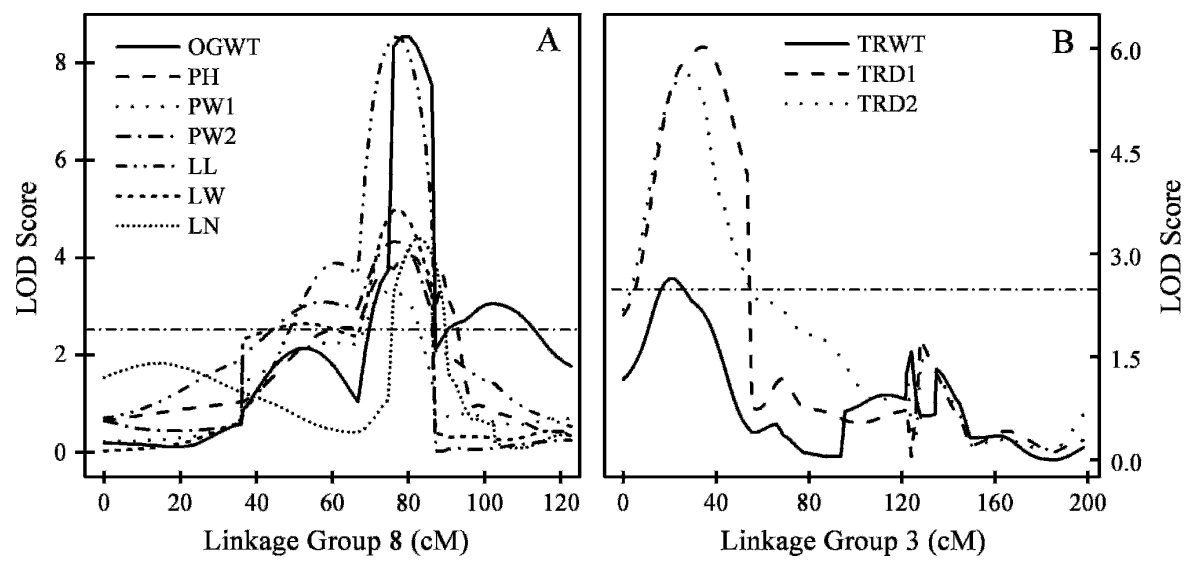

Fig. 2. Comparison of the QTL LOD scores between related traits. TRWT = taproot weight; TRD1 = taproot diameter 1; TRD2 = taproot diameter 2; OGWT=overground weight; $\mathrm{PH}=$ plant height; PW1 = plant width 1 ; PW2 = plant width $2 ; \mathrm{LL}=$ leaf length; $\mathrm{LW}=$ leaf width; $\mathrm{LN}=$ leaf number; QTL $=$ quantitative trait locus; LOD $=$ logarithm of odds.

interacting markers were within $50 \mathrm{cM}$ of each other. The distribution of the remaining 444 interactions for each trait was 27 for BM, 32 for OGWT, 39 for PH, 44 for PW1, 43 for PW2, 37 for LL, 49 for LW, 63 for LN, 37 for TRWT, 32 for TRD1, and 41 for TRD2. Seventy-six of the remaining 444 interactions were also significant at 0.001 level, three for $\mathrm{BM}$, three for OGWT, two for $\mathrm{PH}$, eight for PW1, 11 for PW2, five for LL, 10 for LW, 15 for LN, nine for TRWT, six for TRD1, and four for TRD2. If the filter was set as $P<$ 0.0005 , there were still 43 significant interactions for the 11 traits (data not shown).

These epistases were plotted in Figure 3, in which dark square means $P$ value $<0.001$ and gray square means 0.001 less than $P$ value $<0.005$. It could be observed that some of these epistases were shared by the highly correlated traits, e.g., TRD1, TRD2 and TRWT, BM and OGWT, PW1 and PW2, and so on.

\section{Discussion}

As an important genetic phenomenon, heterosis has been well recognized in many species, including Brassica genus. In our study, the intersubspecific hybrid of $B$. rapa exhibited a great amount of MPH in most traits investigated (Fig. 1). It will provide great significance to elucidate the genetic factors involved in heterosis.

A total of 23 main effect QTLs were detected in this study, and $\approx 65 \%$ of them exhibited obvious overdominance. For composite traits, all QTLs for TRWT showed overdominance, whereas QTLs for BM and OGWT showed only partial dominance. As for the component traits, $85 \%$ of the QTLs for OGWT showed overdominance and only one-fourth for TRWT did so. This finding is generally in agreement with the results of $\mathrm{Li}$ et al. (2001) that most QTLs contributing to heterosis appeared to be overdominant. Although it is quite different from the results of Yu et al. (1997) that more overdominances were observed for yield than for yield component traits, this discrepancy may be largely attributed to the difference in species. These results suggested that 1) overdominance contributes significantly to the genetic basis of heterosis, and 2) the genetic basis for quantitative traits is very complex and an exclusive criterion based on single locus analysis is not competent to explain it.

Two locus epistases were ubiquitous in our study. A total of 444 interactions were detected at $P<0.005$ level with an average of 40 epistases per trait. Some of them remained significant at more stringent levels. This is in accordance with the result of $\mathrm{Li}$ et al. (2001) that most QTL associated with heterosis in rice appeared to be involved in epistasis. As a result of the insufficient informativeness of dominant markers used in this study, further partitions of epistases into AxA, AxD, DxA, and DxD were not available. Luo et al. (2001) reported that the epistatic QTL explained a much greater portion of the total variation than the main effect QTL. Malmberg et al. (2005) also indicated that epistatic QTLs and 

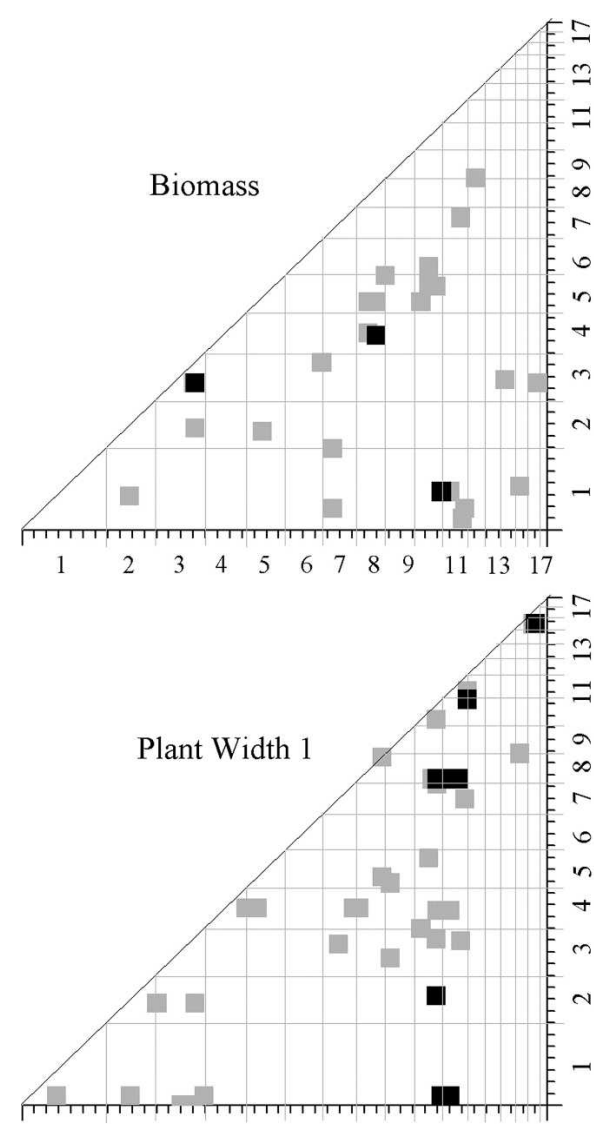

$\begin{array}{llllllllllllll}1 & 2 & 3 & 4 & 5 & 6 & 7 & 8 & 9 & 11 & 13 & 17\end{array}$

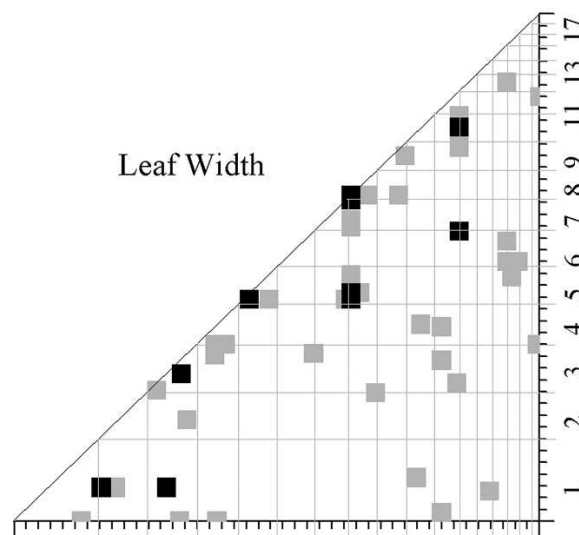

$\begin{array}{llllllllllll}1 & 2 & 3 & 4 & 5 & 6 & 7 & 8 & 9 & 11 & 13 & 17\end{array}$

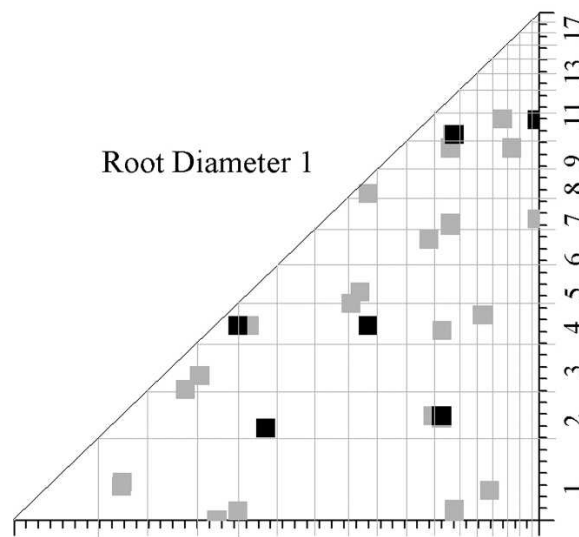

$\begin{array}{lllllllllllll}1 & 2 & 3 & 4 & 5 & 6 & 7 & 8 & 9 & 11 & 13 & 17\end{array}$
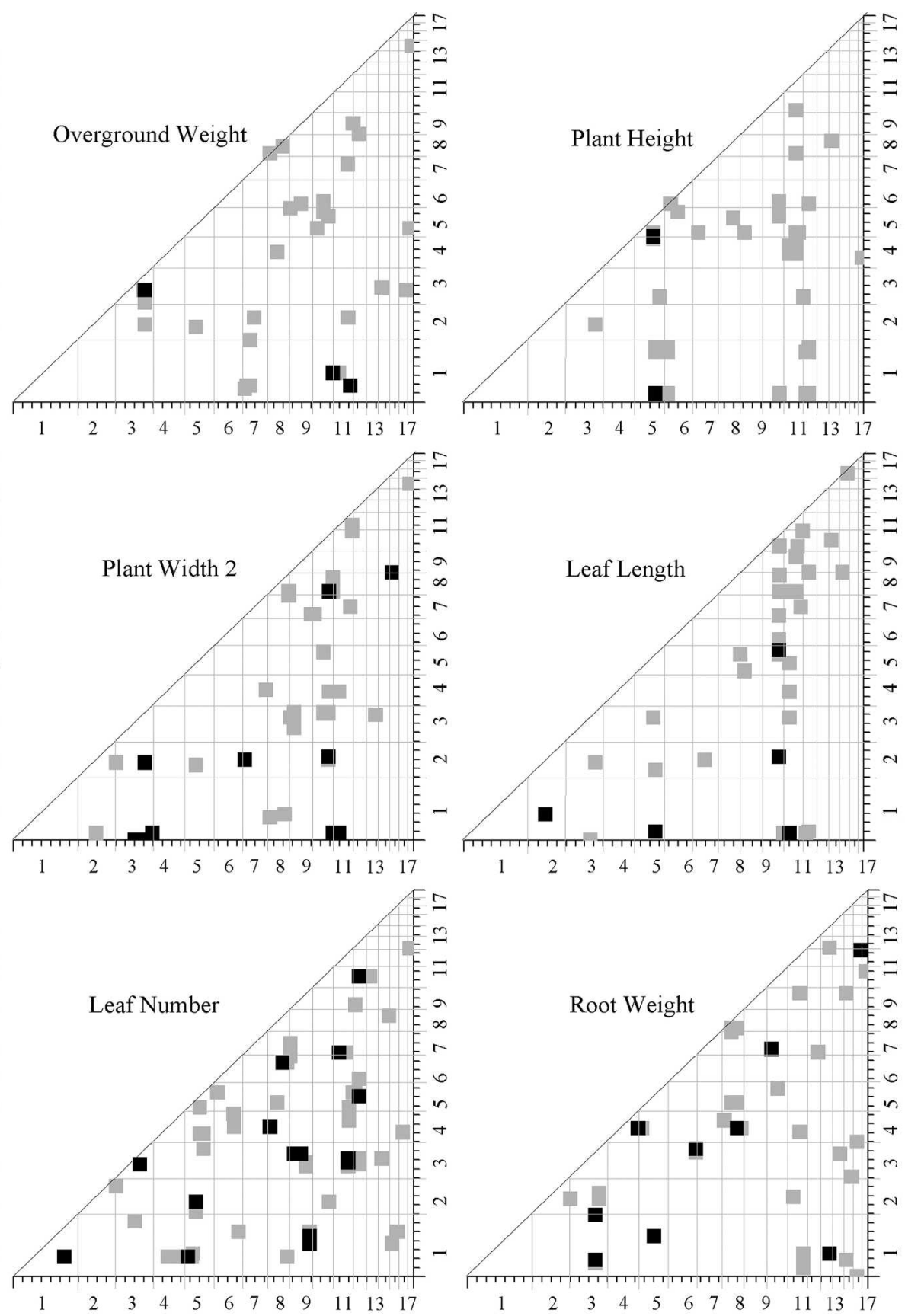

$P$-value $=0.005$

$P$-value $=0.001$

Fig. 3. Two locus interactions detected by EPISTACY for 11 traits investigated. The axes indicate the genetic map of $B$. rapa with one linkage group following another so that the total is display linearly. The plotted squares indicate the $P$ value for an interaction between makers: dark square means $P$ value $<0.001$ and gray square means 0.001 less than $P$ value $<0.005$. 
interactions are approximately twice as many as additive QTLs, and the effects of epistatic interactions are approximately double those of additive QTLs. All these evidences suggested that epistasis is a crucial factor for quantitative traits and might play an important role in the formation of heterosis.

There were also some connections between QTLs of different traits. Close positions and similar effects of QTLs could be observed between many traits, especially between pairs of traits and composite/component traits (Table 1; Fig. 2). Similar results have been reported by Zhuang et al. (2002) in rice. Interestingly, the distribution of two locus interactions also showed some resemblance; many epistases were shared by closely related traits (Fig. 3). It seems likely that some QTLs contribute to more than one trait, especially closely related traits.

The $F_{2}$ population was used for genetic analysis in this study because it theoretically provides the most complete information for genetic analysis. Other populations such as recombinant inbred lines, double haploid, or backcross populations also can be used for genetic analyses. However, these populations are incomplete in terms of genotypic composition and cannot provide estimates for some of the genetic components that are necessary for revealing the genetic basis of heterosis. Whereas the $F_{2}$ populations also have some disadvantages (Hua et al., 2003): 1) each genotype exhibits in single individual, which makes it difficult to measure traits in replications; and 2) the population is in a transient state, so the experiment cannot be repeated. A recently created "immortalized $\mathrm{F}_{2}$ " population (Hua et al., 2003) can successfully overcome these shortcomings and would be helpful to get further insight into the genetic mechanism involved in heterosis.

It should be noted that only one population in one environment was studied in this research for some reasons previously mentioned. So the results obtained here are inevitably limited to some extent. Further studies, especially those on some specific processes related to plant development, will shed new light on the genetic basis underlying heterosis.

In conclusion, this study has demonstrated that overdominance and epistasis are ubiquitous in QTLs of agronomic traits and they might play an important role as the genetic basis of heterosis in B. rapa.

\section{Literature Cited}

Abdelkhalik, A.F., R. Shishido, K. Nomura, and H. Ikehashi. 2005. QTL-based analysis of heterosis for grain shape traits and seeding characteristics in an indica-japonica hybrid in rice (Oryza Sativa L.). Breed. Sci. 55:41-48.

Ali, M., L.O. Copeland, and S.G. Elias. 1995. Relationship between genetic distance and heterosis for yield and morphological traits in winter canola (Brassica napus L.). Theor. Appl. Genet. 91:118-121.

Borevitz, J.O., J.N. Maloof, J. Lutes, T. Dabi, J.L. Redfern, G.T. Trainer, J.D. Werner, T. Asami, C.C. Berry, D. Weigel, and J. Chory. 2002. Quantitative trait loci controlling light and hormone response in two accessions of Arabidopsis thaliana. Genetics 160:683-696.

Brandle, J.E. and P.B.E. McVetty. 1989. Heterosis and combining ability in hybrids derived from oilseed rape cultivars and inbred lines. Crop Sci. 29:1191-1194.

Broman, K.W., H. Wu, S. Sen, and G.A. Churchill. 2003. R/qtl: QTL mapping in experimental crosses. Bioinformatics 19:889-890.

Bruce, A.H. 1910. The Mendelian theory of heredity and the augmentation of vigor. Science 32:627-628.

Chase, K., F.R. Adler, and K.G. Lark. 1997. Epistat: A computer program for identifying and testing interactions between pairs of quantitative trait loci. Theor. Appl. Genet. 94:724-730.

East, E.M. 1908. Inbreeding in corn. Reports of the Connecticut Agricultural Experiment Station for years 1907-1908. p. 419-428.

Falk, K.C., G.F.W. Rakow, R.K. Downey, and D.T Sputt. 1994. Performance of inter-cultivar summer turnip rape hybrids in Saskatchewan. Can. J. Plant Sci. 74:441-445.

Holland, J.B. 1998. EPISTACY: A SAS program for detecting two locus epistatic interactions using genetic marker information. J. Hered. 89:374-375.

Hua, J.P., Y.Z. Xing, W.R. Wu, C.G. Xu, X.L. Sun, S.B. Yu, and Q.F. Zhang. 2003. Single-locus heterotic effects and dominance by dominance interactions can adequately explain the genetic basis of heterosis in an elite rice hybrid. Proc. Natl. Acad. Sci. USA 100:2574-2579.

Jones, D.F. 1917. Dominance of linked factors as a means of accounting for heterosis. Genetics 2:466-479.

Keeble, F. and C. Pellew. 1910. The mode of inheritance of stature and flowering time in peas (Pisum sativum). J. Genet. 1:47-56.

Kosambi, D.D. 1944. The estimation of map distances from recombination values. Ann. Eugen. 12:172-175.

Lander, E., P. Green, J. Abranhamson, A. Barlow, M. Daley, S. Lincoln, and L. Newburg. 1987. MAPMAKER: An interactive computer package for constructing primary genetic maps of experimental and natural populations. Genomics 1:174-181.

Li, B. and R. Wu. 1996. Genetics caused of heterosis in juvenile aspen: A quantitative comparison across intra- and inter-specific hybrids. Theor. Appl. Genet. 93:380-391.

Li, Z.K., L.J. Lou, H.W. Mei, D.L. Wang, Q.Y. Shu, R. Tabien, D.B. Zhong, C.S. Ying, J.W. Stansel, G.S. Khush, and A.H. Paterson. 2001. Overdominant epistatic loci are the primary genetic basis of inbreeding depression and heterosis in rice. I. biomass and grain yield. Genetics 158:1737-1753.

Lincoln, S., M. Daley, and E. Lander. 1992. Constructing genetic maps with MAPMAKER/ EXP 3.0. Whitehead Institute technical report, 3rd ed. Whitehead Institute, Cambridge, MA.

Luo, L.J., Z.K. Li, H.W. Mei, Q.Y. Shu, R. Tabien, D.B. Zhong, C.S. Ying, J.W. Stansel, G.S Khush, and A.H. Paterson. 2001. Overdominance and epistasis loci are the primary genetic basis of inbreeding depression and heterosis in rice. II. Grain yield components. Genetics 158:1755-1771.

Malmberg, R.L., S. Held, A. Waits, and R. Mauricio. 2005. Epistasis for fitness-related quantitative traits in Arabidopsis thaliana grown in the field and in the greenhouse. Genetics 171:2013-2027.

Mitchell-Olds, T. 1995. Interval mapping of viability loci causing heterosis in Arabidopsis. Genetics 140:1105-1109.
OriginLab Corp. 1991-2003. Northampton, MA.

Pradhan, A.K., Y.S. Sodhi, A. Mukeropandhyay, and D. Pental. 1993. Heterosis breeding in Indian Mustard (Brassica juncea L.): Analysis of component characters contributing to heterosis for yield. Euphytica 69:219-229.

Riaz, A., G. Li, Z. Quresh, M.S. Swati, and C.F. Quiros. 2001. Genetic diversity of oilseed Brassica napus inbred lines based on sequence-related amplified polymorphism and its relation to hybrid performance. Plant Breed. 120:411-415

Riungu, T.C. and P.B.E. McVetty. 2004. Comparison of the effect of mur and nap cytoplasms on the performance of intercultivar summer rape hybrids. Can. J. Plant Sci. 84:731-738.

SAS Institute Inc. 2000. SAS Online Doc ${ }^{\circledR}$, ver. 8.0, Cary, NC.

Schuler, T.J., D.S. Hutcheson, and R.K. Downey. 1992. Heterosis in inter-varietal hybrids of summer turnip rape in Western Canada. Can. J. Plant Sci. 72:127-136.

Sen, S. and G.A. Churchill. 2001. A statistical framework for quantitative trait mapping. Genetics 159:371-387.

Shen, J.X., T.D. Fu, G.S. Yang, C.Z. Ma, and J.X. Tu. 2005. Genetic analysis of rapeseed selfincompatibility lines reveals significant heterosis of different patterns for yield and oil content traits. Plant Breed. 124:111-116.

Shull, G.H. 1908. The composition of a field of maize. Rep. Amer. Breed. Ass. 4:296-301.

Song, R. and J. Messing. 2003. Gene expression of a gene family in maize based on noncollinear haplotypes. Proc. Natl. Acad. Sci. USA 100:9055-9060.

Stuber, C.W., S.E. Lincoln, D.W. Wolff, T. Helentjarisn, and E.S. Lander. 1992. Identification of genetic factors contributing to heterosis in a hybrid from two elite maize inbred lines using molecular markers. Genetics 132:823-839.

Teklewold, A. and H.C. Becker. 2005. Heterosis and combining ability in a diallel cross of Ethiopian mustard inbred lines. Crop Sci. 45:2629-2635.

Wang, D.L., J. Zhu, Z.K. Li, and A.H. Paterson. 1999. Mapping QTLs with epistasis effects and QTL $\times$ environment interactions by mixed linear model approaches. Theor. Appl. Genet. 99:1256-1264.

Wang, S., C.J. Basten, and Z.B. Zeng. 2006. Windows QTL Cartographer 2.5. Department of Statistics, North Carolina State University, Raleigh, NC. <http://statgen.ncsu.edu/qtlcart/ WQTLCart.htm>. Accessed 24 May 2007.

Xiao, J.H., J.M. Li, L.P. Yuan, and S.D. Tanksley. 1995. Dominance is the major genetic basis of heterosis in rice as revealed by QTL analysis using molecular makers. Genetics 140:745-754.

Yang, J., C.C. Hu, X.Z. Ye, and J. Zhu. 2005. QTLNetwork 2.0. Institute of Bioinformatics, Zhejiang University, Hangzhou, China. $<$ http:// ibi.zju.edu.cn/software/qtlnetwork $>$. Accessed 24 May 2007.

Yu, C.Y., S.W. Hu, H.X. Zhao, A.G. Guo, and G.L. Sunday. 2005. Genetic distances revealed by morphological characters, isozymes, proteins and RAPD markers and their relationship with hybrid performance in oilseed rape (Brassica napus L.). Theor. Appl. Genet. 110:511-518.

Yu, S.B., J.X. Li, C.G. Xu, Y.F. Tan, Y.J. Gao, X.H. Li, Q.F. Zhang, and M.A.S. Maroof. 1997. Importance of epistasis as the genetic basis of heterosis in an elite rice hybrid. Proc. Natl. Acad. Sci. USA 94:9226-9231.

Zhuang, J.Y., Y.Y. Fan, Z.M. Rao, and J.L. Wu. 2002. Analysis on additive effects and additiveby-additive epistasis effects of QTLs for yield traits in a recombinant inbred line population of rice. Theor. Appl. Genet. 105:1137-1145. 